\title{
Modelling of an Additive 3D-Printing Process Based on Design of Experiments Methodology
}

DOI: 10.12776/QIP.V24I1.1435

\author{
José Alberto Eguren, Aritz Esnaola, Gorka Unzueta
}

Received: 2020-02-29 Accepted: 2020-03-29 Published: 2020-03-31

\begin{abstract}
Purpose: The implementation of additive manufacturing (AM) or 3D-printer manufacturing for technical prototyping, preproduction series and short production series can bring benefits in terms of reducing cost and time to market in product development. These technologies are beginning to be applied in different industrial sectors and have a great possibility of development. As these technologies are still in development, there is a need to define the capacity of the 3D machines to establish minimum standards for producing high-quality parts. In order to understand the behaviour of the different parameters of the 3Dmanufacturing process and define the numerical prediction models to produce high-quality parts, the University of Mondragón has carried out the study presented in this article on a new 3D printer recently purchased for the research laboratories.
\end{abstract}

Methodology/Approach: The proposed methodology is based on a design of experiments (DOE) approach, which serves as a guide for engineers when it comes to executing any experimental study.

Findings: The study has improved understanding in two areas of action: the behaviour of 3D technologies and the application of improvement methods based on the DOE methodology. We identified key factors for optimising the new technology, including an impression in 3D.

Originality/Value of paper: This study uses a methodological approach to demonstrate how the 3D printing technology can be enriched with statistical testing techniques (DOE). It defines numerical prediction models to obtain highquality parts with a new AM technology, using a planning process with a minimum amount of experimentation.

Category: Case study

Keywords: quality improvement; DOE; 3D printer; additive manufacturing 


\section{INTRODUCTION}

Additive manufacturing (AM) is the formalised term used for rapid prototyping, which describes a process used to create systems or parts rapidly before the final presentation of the product. The term '3D printing', describes the processes of converting a 3D computer-aided design (CAD) model into a stereo lithography (STL) triangular lattice surface model, and then creating the solid parts through layer-upon-layer production. In this way, AM changes the way industrial companies operate. This technology is in the early stages of development, so manufacturers are prudent.

This process has mainly been used to create prototypes quickly to verify the details before beginning the formal production process (Gibson, Rosen and Stucker, 2015). The possibility of obtaining parts with better characteristics is currently being studied as an alternative production method that can compete with traditional parts and processes (Narang and Chhabra, 2017; Rayegani and Onwubolu, 2016).

The implementation of AM for technical prototypes, preproduction series and short series of production can offer benefits in terms of cost reduction and reduction of time to market in product development (Khajavi, Partanen and Holmström, 2014; Li, Kucukkoc and Zhang, 2017). These technologies have applied in different industrial sectors and have a strong potential for development. Additive manufacturing is increasingly becoming a true production process, used to create end-use products. That is why speed and quality have also become increasingly important (Moreau, 2018). One of the industrial sectors where AM has experienced great development is the equipment goods sector, which has adopted AM as a method of prototyping and production. In addition, many of the benefits of AM are related to problems of production: in the equipment goods sector, for example, in the equipment goods sector, for example, time reduction and more pressing issues than they are in other industrial sectors. For this reason, AM is seen as a key manufacturing method for the equipment goods sector (Moreau, 2018).

To be competitive in the global markets, manufacturers must have complex and flawless manufacturing processes and reliable supply chains to deliver highquality final products. Manufactured components must demonstrate indisputable performance before use in highly regulated industries, where lives can be affected. Additive manufacturing products will be increasingly competitive with improvements in processing, performance, scalability, affordability and qualification. High-precision computational models will improve the design and processing of AM products. To enable validation, models must be able to predict the exact properties of the product reliably based on the processing parameters (Office of Technology Transition, 2019).

There is currently not enough practice and knowledge available to develop serial manufacturing processes related to AD technologies efficiently. It is necessary to have a thorough knowledge of the technologies used and their influence on the 
final properties of the components. Therefore, methods are required to support the generation of a technological knowledge base and identify the cause-effect relationships of the $\mathrm{AD}$ machines process parameters with the outputs obtained to establish the minimum standards required to produce high-quality parts (Cruz et al., 2014; Rayegani and Onwubolu, 2016). For this reason, it is necessary to analyse and evaluate the capacity of the machines to establish minimum performance standards (Narang and Chhabra, 2017).

Robust modelling tools, high-performance computing and experimental observations can help verify existing models and identify new physical processes and their implications. For this, tools based on modelling of the DOE can help accelerate the development and modelling of the $\mathrm{AD}$ processes and allow efficient homologation of the manufactured parts. By improving these aspects of $\mathrm{AM}$, the DOE allows distributed AM to increase the efficiency of the supply chain significantly (Wiemer et al., 2017).

This article presents the results of a study carried out on a new 3D printer recently acquired for the research laboratories of the University of Mondragón. The main objective of this article is to develop an understanding of the behaviour of the different parameters of fusion deposition modelling (FDM) technology framed within $\mathrm{AD}$ technologies. To this end, a methodological approach has been developed to demonstrate how it can be enriched with statistical testing techniques, such as DOE, and define numerical prediction models to obtain highquality parts. The current study focused on the industrial sector of capital goods, specifically on manufacturing moulds for vacuum-assisted infusion processes. These moulds are applied in the manufacturing of skateboard and drone structures.

This article is structured as follows. In section 2, the application of the proposed methodology in the case of the AM is described. Subsequently, in section 3, a general overview of AM processes is provided. The DOE development for the case is discussed in section 4, and the conclusions and final perspectives are presented in section 5 .

\section{METHODOLOGY}

State of the art DOE offers numerous established algorithms, which can be applied to various technological development tasks. However, in practice, there are often serious obstacles that must be overcome to use these algorithms. The availability of software tools for DOE is not the main problem since there are numerous software tools for the statistical DOE. In the case in question, an analysis was conducted with Minitab 18 software, which offers the possibility of applying the DOE algorithms in a simple way. However, only mathematicians or engineers with additional qualifications can use these algorithms properly. It is quite difficult for an engineer to select the best DOE algorithm for a task in question and parameterise the design. The main reason for this is that 
experimental tasks and the requirements for the necessary analysis results are quite complex, so many engineers avoid using them. This means that the potential offered by DOE methods focused on generating maximum knowledge with minimum effort is not fully utilised (Wiemer et al., 2017).

In addition, in an AM process, the parts produced must simultaneously meet different types of mechanics and dimensional requirements. To address this problem, the research community has used the DOE to optimise the individual manufacturing parameters of the machines. However, the selection of a combination of machine and process parameters to meet multiple requirements simultaneously has not been addressed. There is then a need to investigate a systematic experimental approach to meet multiple production requirements simultaneously and characterise manufacturing capabilities, as proposed in a similar manufacturing context (Ituarte et al., 2015). To this end, the methodology shown in Figure 11 is proposed to address the DOE in the present study (Unzueta et al., 2019). This serves as a guide for engineers when it comes to execute any experimental study based on the DOE. The proposed methodology steps are described in the following paragraphs.

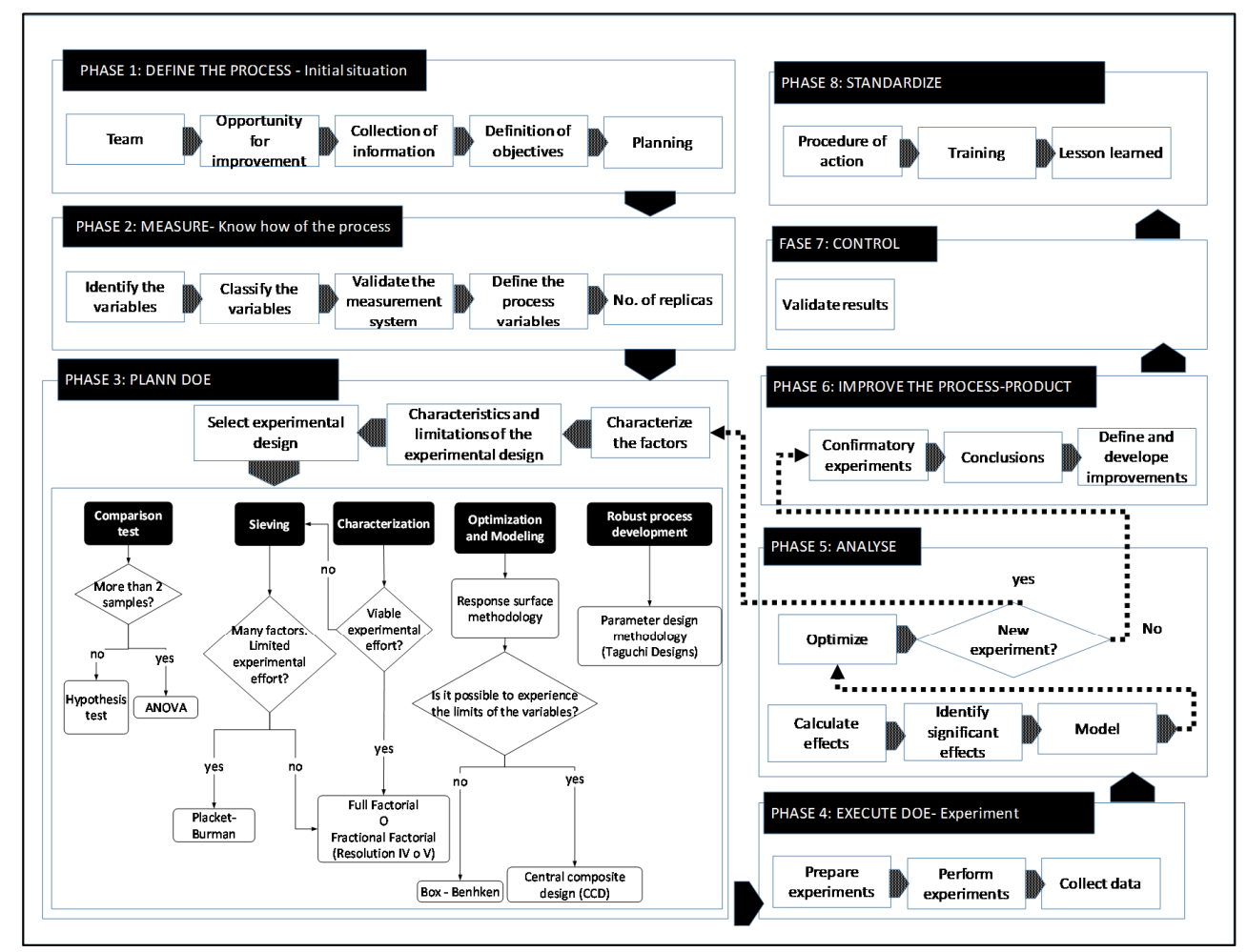

Figure 1-Methodology for the Application of the DOE

(Source: Unzueta et al. (2019)) 


\section{Phase 1: Define}

In this phase, the work team, the process and related information, and the objective of the experimentation are defined. The team must be composed of members familiar with the process for analysis who are able to identify the factors that can influence the response. Usually, the collection of information consists of identifying the parameters of the normal operation of the process.

\section{Phase 2: Measure}

In this phase, the process factors that influence the output are identified and classified to obtain the maximum information that allows for the minimum experimental effort. These are classified as controllable factors and noncontrollable factors (noise). The controllable factors include those the experimenter can consciously modify regarding the level of functioning in each experiment. For the factors identified as non-controllable, a strategy must be defined to reduce their influence and attempt to keep them constant.

\section{Phase 3: Plan}

To select the appropriate experimental design, it is necessary to consider the characteristics and limitations of the process:

- The total number of experiments that can be executed considering the constraints of the process (experimental effort);

- The number of factors, controllable and non-controllable;

- The experimental range and levels of experimentation factors.

Depending on the characteristics of the process and the objective pursued, the appropriate experimental design is selected.

In the flow diagram of Phase 3 (Figure 1), different options are presented based on the objective pursued:

- To compare different situations, a comparison test can be carried out;

- To analyse the process when there is a limit to the number of experiments to be executed, a sieving design can be used to discard the less influential factors;

- To determine the influence of a certain number of factors with sufficient availability of resources, a characterisation based on factorial designs can be carried out;

- To optimise and to model the process with significant factors at more than two levels, a response surface methodology can be used;

- To develop robust processes, the experimental designs of Taguchi can be used.

\section{Phase 4: Execute experimentation}

In this phase, experiments are prepared and executed in the most rigorous and methodical way possible. 


\section{Phase 5: Analyse the results of the experimentation}

The analysis of the results of the experimentation is based on the calculation of the effects of each factor and the factor's influence on the response of the process. The effect of a factor on the response is defined as the variation observed in the response by varying the level of the factor.

By applying the methodology, it is possible to determine the model of the process within the experimental zone used. When the calculations are completed, the coefficients of the polynomial model are defined (without quadratic terms), in the form shown in equation (1):

$$
Y=\beta_{0}+\beta_{1} A+\beta_{2} B+\beta_{3} C+\beta_{4} A B+\beta_{5} A C+\beta_{6} B C
$$

Where, $\beta_{0}$ is the average of the result of the experiments. $\beta_{i}$ is the coefficient of each factor (half of the calculated effect). The values $A, B$, and so forth are the values that each factor or interaction takes $(+1,-1)$.

\section{Phase 6: Improve via confirmation experiments}

In this phase, once the optimisation is completed, confirmatory experiments are carried out to confirm the levels of each factor identified as adequate.

\section{Phases 7-8: Control and standardise}

In these phases, once the significant factors and the levels that improve the response are defined, it is necessary to standardise the process and determine the controls that ensure the maintenance of adequate levels.

\section{ADDITIVE MANUFACTURING}

Additive manufacturing is a new group of technologies that, although still evolving, are projected to exert a profound impact on manufacturing. They can give industry new design flexibility, and shorten time to market. All AM technologies involve several processes, but these processes are often similar. In general, AM technologies involve eight different stages, which include creating the CAD model, converting this design to the STL format, transferring this format to the AM machine, configuring the machine, building parts, removing the pieces produced in the machine, and, if necessary, post-processing and using applications for additional treatments, such as painting and priming (Kumbhar and Mulay, 2018; Wong and Hernandez, 2012).

The first task is to develop an idea and to visualise it. It is possible to visualise any type of product with a CAD model. Next, to avoid issues related to unreliable products not completely included, it is necessary to change the CAD model to an STL format, which creates the geometry of the surface of the object using triangles in three dimensions without any representation of colour, texture or other attributes of the model. After creating this file, it is necessary to send this 
document to the AM machine to create it immediately. After configuring the machine, the process will continue with the computer-controlled construction phase. In this phase, the AM machine begins to produce the object that is recognised by the machine. Following this step, the producer removes the object from the machine and cleans it for further processing. Most parts made with additives will require further processing. In this step, the object is prepared for the client's use by painting it, polishing it, sanding it, and so forth (Wong and Hernandez, 2012).

This technology, which was first introduced in 1987, is still considered new and continues to be developed with new methods and materials, according to the sector. Over time, AM has been adopted by new sectors, which means that new types of AM technologies will continue to be developed. This technology is already used in many sectors, including architecture, medicine, automotive, aerospace, transportation, art, energy, commercial products, defence, education and electronics (Gausemeier, Wall and Peter, 2013; Wong and Hernandez, 2012).

Additive manufacturing has been used in the medical sector almost since its inception. The first of the AM applications in the medical sector was the use of computerised tomography to create images of subjects from any angle. In addition, AM has been applied in different categories of medical applications, such as for surgical and diagnostic aids, prosthesis development, and manufacturing related to medicine and tissue engineering (Chepelev et al., 2017; Tofail et al., 2018).

The aerospace sector is another sector that has used AM since its initial introduction. The aerospace sector uses complex geometric shapes that are difficult to produce, requiring many steps to produce a piece; however, with the application of AM, many steps can be omitted. This is the biggest reason that AM is favoured in this sector, but there are many other reasons to apply this technology in this sector as well: AM can be used to produce light parts, complex shapes and digital parts, and can reduce the cost of production because it does not produce the same parts required by conventional manufacturing processes (Lipson et al., 2012). In the automotive sector, AM was also used to produce parts, but most manufacturers decided not to pursue this technology for the mass production of automobiles due to the high cost of production (Dwivedi, Srivastava and Srivastava, 2015).

The materials used in the first applications of AM were plastics, but after further developments, metals, ceramics and composites of these materials are now also being used for this technology. Following such developments, AM has continued to evolve rapidly, and today is applied in many sectors. Metals are being used in the form of completely molten particles. Specifically, SnS, Ti6Al4V, stainless steel 316L, 17-4 PH, tool steels, nickel alloys, cobalt alloys and titanium alloys are examples of metal materials used in AM technology. Polymers also are being used in AM, which have been used since the introduction of this technology. Plastics, acrylic plastics, wax, ABS, photo-curable resins, polyamide, 
polystyrene, ULTEM and PC are examples of polymer materials used in AM. Ceramics are also widely used in AM, but it is difficult to use them to produce complex parts because they have a high degree of hardness and brittleness. Specifically, zirconia, silica, alumina, PZT, bioceramic, sand, graphite and industrial ceramics, such as Si3N4 and Al2O3, are used. Composites are engineered or naturally occurring materials made from two or more constituents, and they are widely used in AM technologies. Some composite materials used include $\mathrm{Fe}-\mathrm{Cu}$, TiC-Ni, steel-Cu, polymer matrix and fibre-reinforced composites (Guo and Leu, 2013).

There are various ways to classify the AM technologies, such as by baseline technologies or by their raw material input; however, using one type of classification seems to provide a better understanding of the technology. In 2010, the American Society for Testing and Materials (ASTM) group "ASTM F42AM" (Harris, 2019) formulated a set of standards that classify the range of AM processes into seven categories: vat photopolymerisation, material jetting, binder jetting, material extrusion, powder bed fusion, sheet lamination and directed energy deposition (Kumbhar and Mulay, 2018).

Additive manufacturing faces many challenges and barriers; they must be overcome in order to integrate this technology as amongst the current manufacturing processes. Some challenges are related to the development of process control systems in order to incorporate feedback control systems, and metrics to improve accuracy, reliability and quality. There is also a need to improve the manufacturing price in order to be able to machine parts on micron scales or produce quality pieces in terms of surface finishes, which can achieve the desired tribological and aesthetic properties.

Processing speed is another challenge to overcome in order to develop highperformance additive processing methods to compete with conventional techniques. Additionally, the capacity to produce large volumes, both in size and in the number of pieces produced, must be addressed. Finally, the development of processes capable of producing products with new metallic materials and polymers formulated for AM, which provide specific application properties, such as flexibility, conductivity and transparency, stands out (Office of Technology Transition, 2019).

\section{DESIGN OF EXPERIMENTS: DEVELOPMENT FOR THE CASE}

The results described in the following paragraphs are the consequence of the application of the DOE methodology on the case study, following the steps described in section 3 . 


\section{Phase 1: Definition of the case study}

Fused deposition modelling (FDM) is a leading AM technology that is grouped into the category of extrusion-based systems used to manufacture solid prototypes with various materials directly from CAD data. Extrusion is a method used to create objects of a fixed cross-sectional profile. As the name implies, extrusion-based systems create parts by successively depositing layers via the controlled flow of a semi-liquid raw material through a nozzle in the deposition head assembly. The resulting material will maintain a constant cross-sectional diameter. Next, the AM machine starts and stops the flow of the material while scanning to complete the layer and then adds additional layers (Gibson, Rosen and Stucker, 2015).

The quality and strength of FDM construction parts depend essentially on the process parameters. To understand the performance and behaviour of FDM construction parts, the influence of process parameters on the quality of the result of construction parts must be studied (Venkatasubbareddy, Siddikali and Saleem, 2016). For this case study, the FDM process was used to create the samples. This process was performed in the laboratories of Mondragón University, as shown in Figure 2.

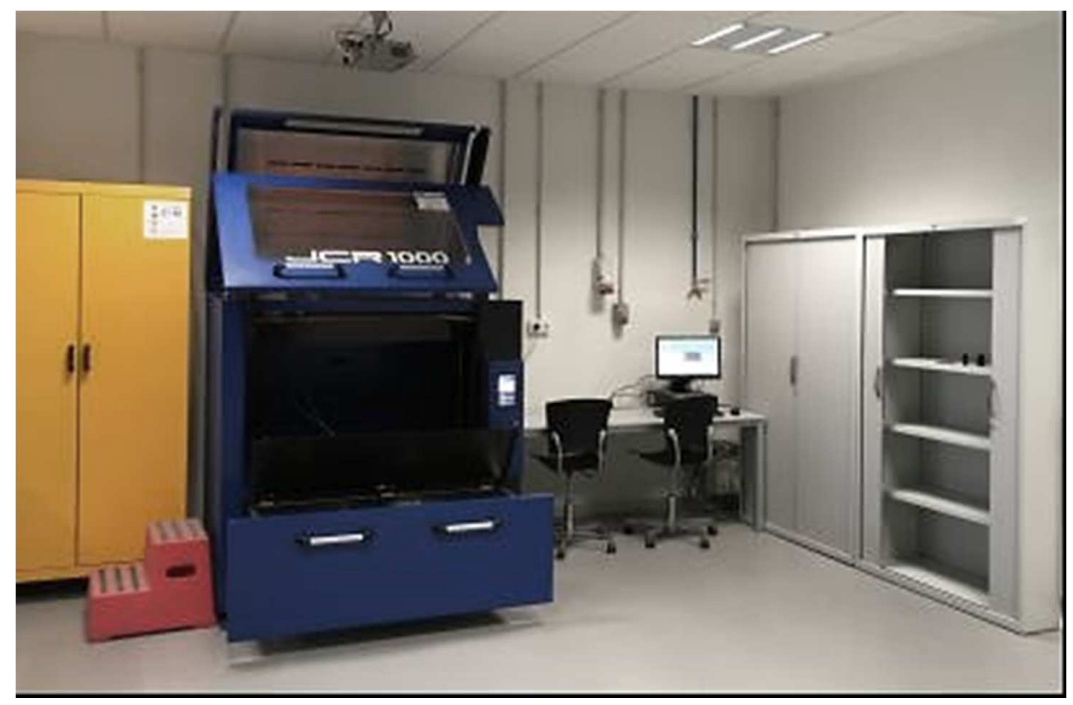

Figure 2 - Fused Deposition Modelling Equipment Acquired by the Laboratories of Mondragón University

The part created for the case study had a standard design analysed by the tensile test. To verify the mechanical properties of the composite material, the 3D model of the tensile test specimen was created according to EN ISO 527-2 standard (ISO, 2012). All the parts were made from polylactic acid (PLA). This material is a thermoplastic polymer. It is a standard polymer used in 3D printing with FDM technology. This material has some advantages: it is biodegradable because it is derived from renewable feedstock, such as starch, and its contraction during the 
cooling phase is weak. It has good geometrical stability during its fabrication, and it uses low temperature to transform (merger point around $180^{\circ} \mathrm{C}$ ). Generally, PLA is used for the creation of objects for the food processing industry or decoration without mechanical stress. In Figure 3, the dimensions of the sample tested are shown.

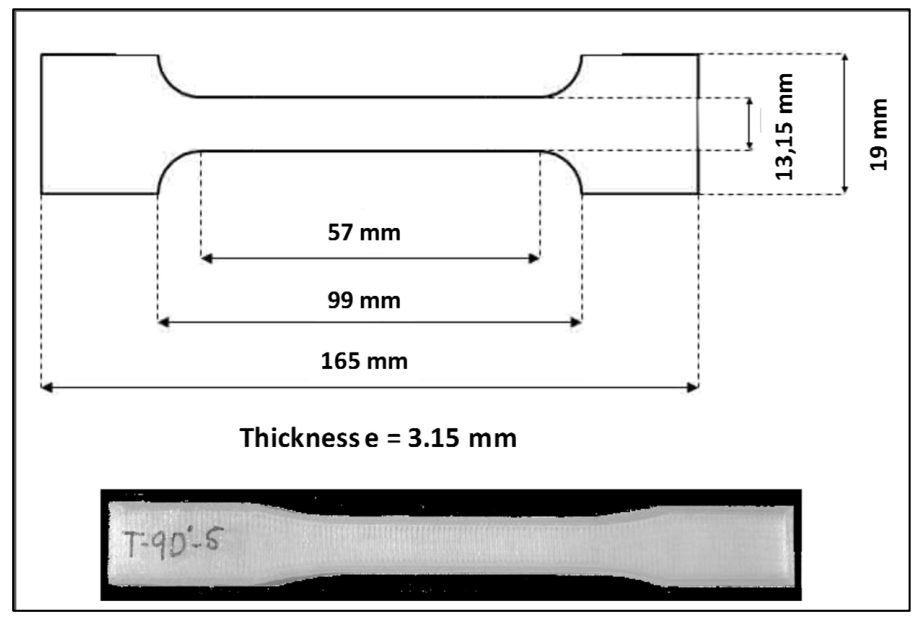

Figure 3 -Dimensions of the Sample Tested

To evaluate the mechanical properties of the created specimens, tensile tests were carried out in the laboratory of Mondragón University according to EN ISO 527. The machine used for the tensile test was the Instron by Zwick/Roell, which is shown in Figure 4.

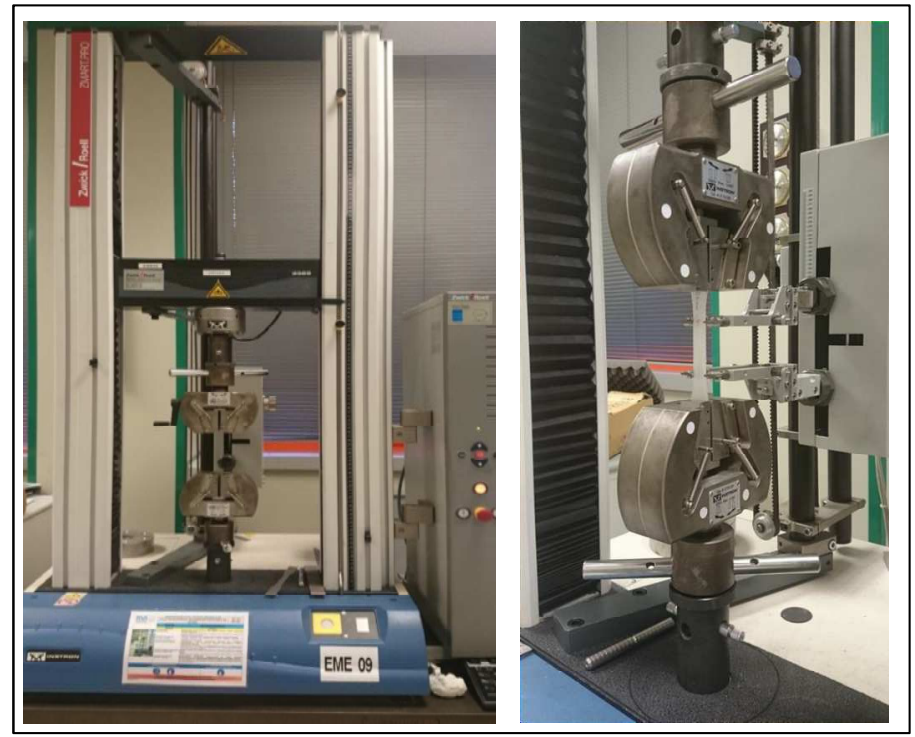

Figure 4 - Machine Used for the Tensile Test 


\section{Phase 2: Measurement of the case study}

The quality and strength of FDM construction parts depend essentially on the process parameters. To understand the performance and behaviour of FDM construction parts, the influence of process parameters on the quality of the result of construction parts must be studied. Numerous studies have been carried out in this field, where the most important parameter levels of the FDM have been analysed for different quality characteristics of the construction pieces, including the thickness of the layer, air space, width of the plot, plot orientation, temperature and deposition rate (Sood, Ohdar and Mahapatra, 2010; Anitha, Arunachalam and Radhakrishnan, 2001; Prasad, Krishna and Venkatasubbareddy, 2014; Venkatasubbareddy, Siddikali and Saleem, 2016).

In the present study, the aforementioned information has been taken as a basis and brainstorming has been carried out to identify new factors. Strategies to be followed for each factor have been assigned. Table 1 shows the most important factors that affect the process and its classifications.

Table 1 - The Most Important Factors that Affect the Process and Their Classifications

\begin{tabular}{|c|c|c|c|c|c|c|}
\hline $\mathbf{N}^{\mathbf{0}}$ & Factor & $\begin{array}{c}\text { Factor } \\
\text { type }\end{array}$ & Classification & Strategy & $\begin{array}{l}\text { Expecte } \\
\text { d effect }\end{array}$ & Factor range \\
\hline 1 & Extruder temperature & Continuous & Controllable & Control & Positive & $180-200{ }^{\circ} \mathrm{C}$ \\
\hline 2 & $\begin{array}{l}\text { Nozzle movement } \\
\text { speed }\end{array}$ & Continuous & Controllable & Control & Negative & $\begin{array}{c}40 \mathrm{~mm} / \mathrm{sec}-80 \\
\mathrm{~mm} / \mathrm{sec}\end{array}$ \\
\hline 3 & Thickness of Layer & Continuous & Controllable & Control & Positive & $0.1 \mathrm{~mm}-0.3 \mathrm{~mm}$ \\
\hline 4 & Extrusion Width & Continuous & Controllable & Control & Positive & $0.55-0.75$ \\
\hline 5 & Test Tube Position & Discrete & Controllable & Control & Positive & $\begin{array}{c}\text { Horizontal - } \\
\text { Vertical }\end{array}$ \\
\hline 6 & Internal fill angle & Discrete & Controllable & Control & & $0^{\circ}-90^{\circ}$ \\
\hline 7 & Nozzle type & Discrete & Controllable & $\begin{array}{c}\text { Use the nozzle, } \\
\text { recommended by } \\
\text { the manufacturer }\end{array}$ & $\begin{array}{c}\text { Null } \\
\text { influence }\end{array}$ & 0.6 \\
\hline 8 & Material & Discrete & Controllable & $\begin{array}{l}\text { Use the same } \\
\text { material }\end{array}$ & $\begin{array}{c}\text { Null } \\
\text { influence }\end{array}$ & $\begin{array}{l}\text { Polylactic acid } \\
\text { PLA }\end{array}$ \\
\hline 9 & $\begin{array}{l}\text { Overlap: last layer - } \\
\text { perimeter }\end{array}$ & Continuous & Controllable & $\begin{array}{c}\text { Use the same } \\
\text { value }\end{array}$ & $\begin{array}{c}\text { Null } \\
\text { influence }\end{array}$ & 0,15 \\
\hline 10 & First layer $($ speed,...$)$ & Continuous & Controllable & $\begin{array}{c}\text { Use the same } \\
\text { value }\end{array}$ & $\begin{array}{c}\text { Null } \\
\text { influence }\end{array}$ & $\begin{array}{c}\text { Established by the } \\
\text { manufacturing } \\
\text { CNC program }\end{array}$ \\
\hline 11 & $\begin{array}{l}\text { Position on the table } \\
\text { (quadrant) }\end{array}$ & Discrete & Controllable & $\begin{array}{l}\text { Use the same } \\
\text { position }\end{array}$ & $\begin{array}{c}\text { Null } \\
\text { influence }\end{array}$ & \\
\hline 12 & Cooling & Continuous & Noise & \begin{tabular}{|c|} 
Fans running, to \\
cool the \\
environment \\
inside the printer
\end{tabular} & & \\
\hline 13 & Ambient temperature & Discrete & Noise & Randomize & & \\
\hline 14 & Ambient humidity & Discrete & Noise & Randomize & & \\
\hline 15 & $\begin{array}{l}\text { Humidity, raw } \\
\text { material }\end{array}$ & Discrete & Noise & Randomize & & \\
\hline
\end{tabular}


The definitions of the controllable factors selected in this study are as follows:

- Temperature: Heat degree present to manufacture a product using 3D machines. Temperatures that are considered suitable by testers are $180^{\circ}$ and $200^{\circ}$.

- Speed: Indicates how fast the filament is pulled back from the nozzle. The lowest level of speed for manufacturing is $40 \mathrm{~mm} / \mathrm{sec}$, and the highest level is $80 \mathrm{~mm} / \mathrm{sec}$.

- Thickness of layer: The nominal layer thickness for most machines is around $0.1 \mathrm{~mm}$; however, it should be noted that this is only a general principle. The reasoning is that thicker layer parts are quicker to build but are less precise. In trials performed by testers, the lower level of thickness was $0.1 \mathrm{~mm}$ and the higher level was $0.3 \mathrm{~mm}$.

- Extrusion width: A process used to create objects of a fixed crosssectional profile. A material is pushed through a die of the desired crosssection. For the current study's case experiments, the lower and higher widths were respectively 0.55 and 0.75 .

- Test tube position: The part orientation on the machine build platform in which geometries are manufactured horizontally or vertically.

- Internal fill angle: The process by which materials are used to fill created pieces (also known as infill). For the current study's case experiments, the special angle was chosen to be $0^{\circ}-90^{\circ}$.

Table 2 shows a summary of the selected controllable factors.

Table 2 - Summary of Controllable Factors Selected

\begin{tabular}{|c|c|c|c|}
\hline \multirow{2}{*}{ Cod } & \multirow{2}{*}{ Variable } & \multicolumn{2}{|c|}{ Experimental level } \\
\cline { 3 - 4 } & & Lower Level & Higher Level \\
\hline A & Temperature & Continuous & Controllable \\
\hline B & Speed (Speed of Movement of the Nozzle) & Continuous & Controllable \\
\hline C & Thickness of Layer & Discrete & Controllable \\
\hline D & Extrusion Width & Discrete & Controllable \\
\hline E & Test Tube Position & Discrete & Controllable \\
\hline F & Infill (solid interior)-Internal fill angle & Discrete & Controllable \\
\hline
\end{tabular}

To conclude this phase, the number of replicas necessary to calculate the experimental error and analyse the significance of the effects and interactions was defined. To do this, a hypothesis test was carried out, considering the deviation of the results $(\sigma)$, the maximum expected effect, the probability of a type I error $(\alpha)$ and the sample size (or the number of replicas). In the case of this study, the hypothesis test was performed defining two replicas (common in industrial processes), an expected effect of $20 \%$, and $\alpha=5 \%$, obtaining a power of 0.96, which was adequate. As shown in Figure 5, two replicates are sufficient to obtain a power greater than $80 \%$ to observe a change in the response greater than $15 \%$ (stress at the moment of breakage $[\mathrm{MPa}]$ ). 


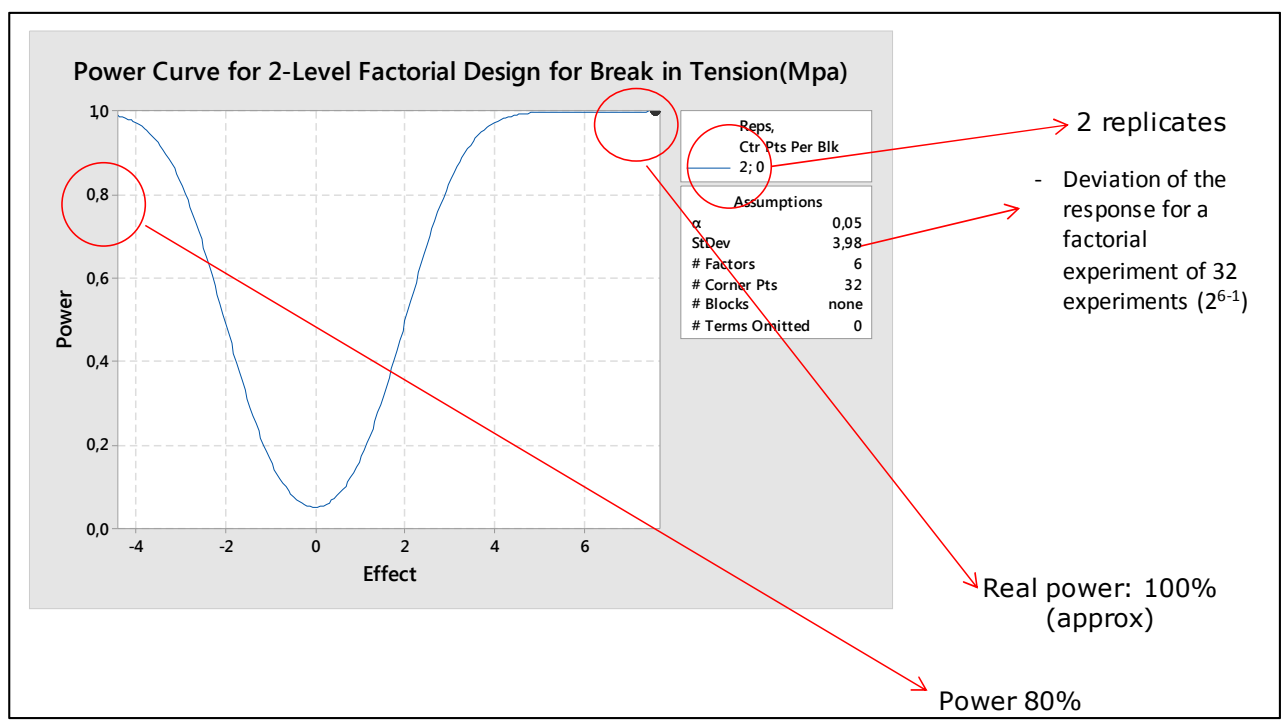

Figure 5-Power Curve to Define the Numbers of Replicas

Phases 3-4: Planning and execution of the case study experiment

Following the indications of the methodology described in Phase 3, the case in question was developed within a context of characterisation, so the experimental strategy used corresponded with the factorial experimental design. Figure 6 shows different examples of the experimentation carried out.

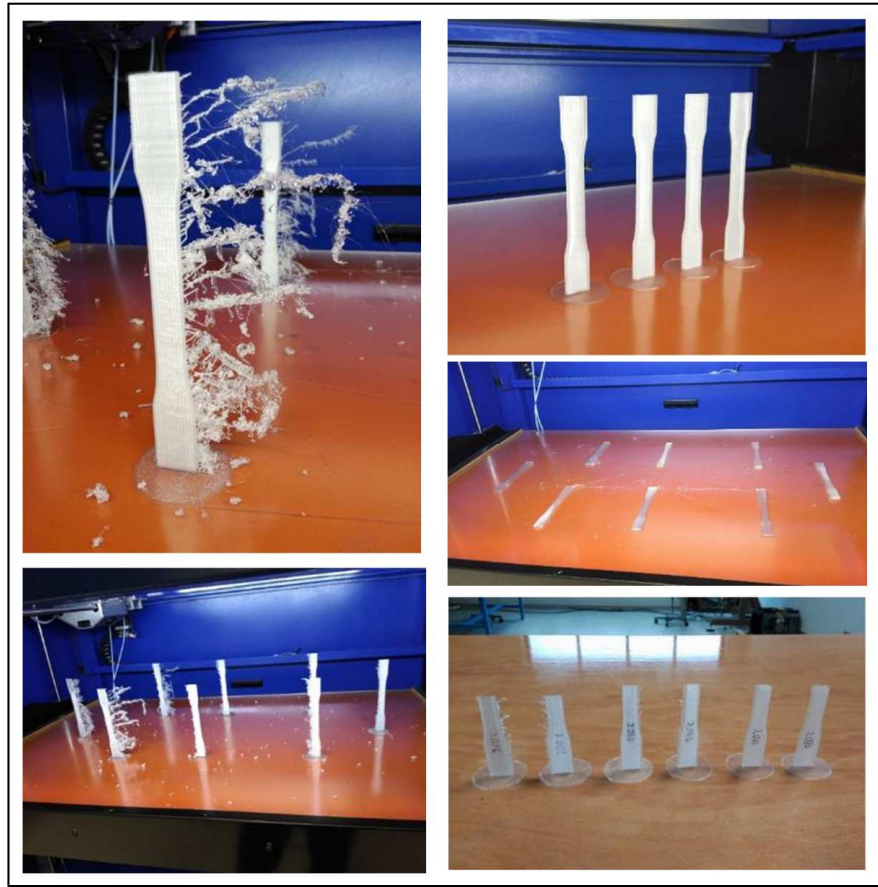

Figure 6-Examples of the Experimentation 
Six controllable factors and two levels for each factor were identified, selecting a fractional factorial design $\left(2^{6-1}\right)$ of resolution IV and two replicates for a total of 64 experiments. Three answers to be analysed were selected: the Young modulus (GPa), break in tension (MPa) and breakage deformation. The experimental design and the results of the experimentation are shown in Figure 7.

\begin{tabular}{|c|c|c|c|c|c|c|c|c|c|}
\hline RunOrder & Temperature & Speed & $\begin{array}{c}\text { Thickness of } \\
\text { Layer }\end{array}$ & $\begin{array}{c}\text { Extrusion } \\
\text { Width }\end{array}$ & $\begin{array}{l}\text { Test Tube } \\
\text { Position }\end{array}$ & $\begin{array}{c}\text { Internal Fill } \\
\text { Angle }\end{array}$ & Young(GPa) & $\begin{array}{c}\text { Break in } \\
\text { Tension(MPa) }\end{array}$ & $\begin{array}{c}\text { Breakage } \\
\text { Deformation }\end{array}$ \\
\hline 1 & 180 & 40 & 0,1 & 0,55 & Horizontal & 0 & 2,70 & 24,10 & 0,01 \\
\hline 2 & 200 & 40 & 0,1 & 0,55 & Horizontal & 90 & 3,13 & 30,71 & 0,01 \\
\hline 3 & 180 & 80 & 0,1 & 0,55 & Horizontal & 90 & 2,53 & 27,42 & 0,01 \\
\hline 4 & 200 & 80 & 0,1 & 0,55 & Horizontal & 0 & 3,07 & 30,64 & 0,01 \\
\hline 5 & 180 & 40 & 0,3 & 0,55 & Horizontal & 90 & 3,34 & 37,85 & 0,01 \\
\hline 6 & 200 & 40 & 0,3 & 0,55 & Horizontal & 0 & 3,34 & 34,10 & 0,01 \\
\hline 7 & 180 & 80 & 0,3 & 0,55 & Horizontal & 0 & 2,47 & 25,06 & 0,01 \\
\hline 8 & 200 & 80 & 0,3 & 0,55 & Horizontal & 90 & 2,82 & 32,25 & 0,01 \\
\hline 9 & 180 & 40 & 0,1 & 0,75 & Horizontal & 90 & 3,28 & 42,33 & 0,01 \\
\hline 10 & 200 & 40 & 0,1 & 0,75 & Horizontal & 0 & 3,17 & 42,70 & 0,02 \\
\hline 11 & 180 & 80 & 0,1 & 0,75 & Horizontal & 0 & 2,90 & 45,98 & 0,02 \\
\hline 12 & 200 & 80 & 0,1 & 0,75 & Horizontal & 90 & 3,07 & 53,49 & 0,03 \\
\hline 13 & 180 & 40 & 0,3 & 0,75 & Horizontal & 0 & 3,31 & 42,74 & 0,01 \\
\hline 14 & 200 & 40 & 0,3 & 0,75 & Horizontal & 90 & 3,08 & 42,57 & 0,02 \\
\hline 15 & 180 & 80 & 0,3 & 0,75 & Horizontal & 90 & 3,40 & 55,63 & 0,03 \\
\hline 16 & 200 & 80 & 0,3 & 0,75 & Horizontal & 0 & 3,60 & 48,41 & 0,02 \\
\hline 17 & 180 & 40 & 0,1 & 0,55 & Vertical & 90 & 2,29 & 32,06 & 0,02 \\
\hline 18 & 200 & 40 & 0,1 & 0,55 & Vertical & 0 & 3,39 & 39,56 & 0,02 \\
\hline 19 & 180 & 80 & 0,1 & 0,55 & Vertical & 0 & 2,49 & 31,36 & 0,01 \\
\hline 20 & 200 & 80 & 0,1 & 0,55 & Vertical & 90 & 3,23 & 43,15 & 0,02 \\
\hline 21 & 180 & 40 & 0,3 & 0,55 & Vertical & 0 & 2,88 & 37,01 & 0,02 \\
\hline 22 & 200 & 40 & 0,3 & 0,55 & Vertical & 90 & 2,95 & 38,03 & 0,02 \\
\hline 23 & 180 & 80 & 0,3 & 0,55 & Vertical & 90 & 2,38 & 34,89 & 0,02 \\
\hline 24 & 200 & 80 & 0,3 & 0,55 & Vertical & 0 & 2,84 & 35,53 & 0,02 \\
\hline 25 & 180 & 40 & 0,1 & 0,75 & Vertical & 0 & 3,14 & 45,46 & 0,02 \\
\hline 26 & 200 & 40 & 0,1 & 0,75 & Vertical & 90 & 3,65 & 55,94 & 0,05 \\
\hline 27 & 180 & 80 & 0,1 & 0,75 & Vertical & 90 & 2,88 & 40,19 & 0,02 \\
\hline 28 & 200 & 80 & 0,1 & 0,75 & Vertical & 0 & 2,89 & 37,14 & 0,02 \\
\hline 29 & 180 & 40 & 0,3 & 0,75 & Vertical & 90 & 3,06 & 43,49 & 0,02 \\
\hline 30 & 200 & 40 & 0,3 & 0,75 & Vertical & 0 & 3,27 & 53,64 & 0,02 \\
\hline 31 & 180 & 80 & 0,3 & 0,75 & Vertical & 0 & 3,38 & 42,96 & 0,02 \\
\hline 32 & 200 & 80 & 0,3 & 0,75 & Vertical & 90 & 3,02 & 42,54 & 0,02 \\
\hline 33 & 180 & 40 & 0,1 & 0,55 & Horizontal & 0 & 2,64 & 18,69 & 0,01 \\
\hline 34 & 200 & 40 & 0,1 & 0,55 & Horizontal & 90 & 3,00 & 18,77 & 0,01 \\
\hline 35 & 180 & 80 & 0,1 & 0,55 & Horizontal & 90 & 3,24 & 18,17 & 0,01 \\
\hline 36 & 200 & 80 & 0,1 & 0,55 & Horizontal & 0 & 2,94 & 20,65 & 0,01 \\
\hline 37 & 180 & 40 & 0,3 & 0,55 & Horizontal & 90 & 2,43 & 17,58 & 0,01 \\
\hline 38 & 200 & 40 & 0,3 & 0,55 & Horizontal & 0 & 3,04 & 21,80 & 0,01 \\
\hline 39 & 180 & 80 & 0,3 & 0,55 & Horizontal & 0 & 3,27 & 20,77 & 0,01 \\
\hline 40 & 200 & 80 & 0,3 & 0,55 & Horizontal & 90 & 3,20 & 23,84 & 0,01 \\
\hline 41 & 180 & 40 & 0,1 & 0,75 & Horizontal & 90 & 3,52 & 50,57 & 0,02 \\
\hline 42 & 200 & 40 & 0,1 & 0,75 & Horizontal & 0 & 3,12 & 33,42 & 0,01 \\
\hline 43 & 180 & 80 & 0,1 & 0,75 & Horizontal & 0 & 3,14 & 38,00 & 0,01 \\
\hline 44 & 200 & 80 & 0,1 & 0,75 & Horizontal & 90 & 3,14 & 45,55 & 0,02 \\
\hline 45 & 180 & 40 & 0,3 & 0,75 & Horizontal & 0 & 3,56 & 48,15 & 0,02 \\
\hline 46 & 200 & 40 & 0,3 & 0,75 & Horizontal & 90 & 3,62 & 55,75 & 0,02 \\
\hline 47 & 180 & 80 & 0,3 & 0,75 & Horizontal & 90 & 3,64 & 56,47 & 0,02 \\
\hline 48 & 200 & 80 & 0,3 & 0,75 & Horizontal & 0 & 3,44 & 55,49 & 0,02 \\
\hline 49 & 180 & 40 & 0,1 & 0,55 & Vertical & 90 & 2,12 & 20,73 & 0,01 \\
\hline 50 & 200 & 40 & 0,1 & 0,55 & Vertical & 0 & 3,83 & 20,31 & 0,01 \\
\hline 51 & 180 & 80 & 0,1 & 0,55 & Vertical & 0 & 3,53 & 30,76 & 0,01 \\
\hline 52 & 200 & 80 & 0,1 & 0,55 & Vertical & 90 & 1,86 & 12,04 & 0,01 \\
\hline 53 & 180 & 40 & 0,3 & 0,55 & Vertical & 0 & 2,23 & 27,14 & 0,01 \\
\hline 54 & 200 & 40 & 0,3 & 0,55 & Vertical & 90 & 1,39 & 9,60 & 0,01 \\
\hline 55 & 180 & 80 & 0,3 & 0,55 & Vertical & 90 & 1,92 & 18,90 & 0,01 \\
\hline 56 & 200 & 80 & 0,3 & 0,55 & Vertical & 0 & 2,84 & 27,87 & 0,01 \\
\hline 57 & 180 & 40 & 0,1 & 0,75 & Vertical & 0 & 2,59 & 28,99 & 0,01 \\
\hline 58 & 200 & 40 & 0,1 & 0,75 & Vertical & 90 & 2,40 & 20,93 & 0,01 \\
\hline 59 & 180 & 80 & 0,1 & 0,75 & Vertical & 90 & 1,86 & 16,94 & 0,01 \\
\hline 60 & 200 & 80 & 0,1 & 0,75 & Vertical & 0 & 1,68 & 14,05 & 0,01 \\
\hline 61 & 180 & 40 & 0,3 & 0,75 & Vertical & 90 & 2,54 & 26,24 & 0,01 \\
\hline 62 & 200 & 40 & 0,3 & 0,75 & Vertical & 0 & 2,57 & 34,97 & 0,04 \\
\hline 63 & 180 & 80 & 0,3 & 0,75 & Vertical & 0 & 2,92 & 42,06 & 0,02 \\
\hline 64 & 200 & 80 & 0,3 & 0,75 & Vertical & 90 & 2,70 & 36,81 & 0,02 \\
\hline
\end{tabular}

Figure 7 - Experimental Design Matrix (26-1, 2 replicas) 


\section{Phase 5: Analysis of the results of the case study experimentation}

When the experiments were analysed, the data were fitted to a model and estimated. The effects of the main factors and interaction terms were estimated. The analysis involved interpreting the influence that each variable had on the result.

Experimentation can be difficult if too many variables are changed at the same time. There are many ways to comment on results that are obtained through data analysis. Pareto charts determine the magnitude and importance of the effects. In the chart, bars that cross the reference line are statistically significant. The Pareto chart displays the absolute value of the effects. It can determine which effects are significant, but it cannot determine which effects increase or decrease the response. This type of chart helped determines that $20 \%$ of the variables were the most influential for $80 \%$ of the results. This information is useful because it helps focus on the variables that have a significant effect.

The normal probability plot of the standardised effects was used to examine the magnitude and direction of the effects on one plot. The normal probability plot of effects shows the standardised effects relative to a distribution fit line for the case when all the effects are 0 . The standardised effects are t-statistics that test the null hypothesis that the effect is 0 . Positive effects increase the response when the settings change from at low value of the factor at the high value. Negative effects decrease the response when the settings change from at low value to at high value of the factor. Effects further from 0 on the $\mathrm{x}$-axis have greater magnitude and are more statistically significant. In the following paragraphs, the results for each analysed response are discussed, for which the Minitab 18 software was used as support.

\section{First answer: The Young modulus ( $\mathrm{GPa}$ )}

Figure 8 shows a summary of the results for the first answer: the Young modulus (GPa). It can be observed that the normal plot graphics are the variable test tube position (E), located at the left side of the graphics, so E has a positive effect on the Young modulus. The extrusion width (D) is fixed at the right side of the graph, which means that $\mathrm{D}$ has a negative effect on the Young modulus. For the Pareto chart, after the red line, variables D and $\mathrm{E}$ appeared. Thus, $\mathrm{E}$ is in the first place and has a greater effect on that response. The main effect plot graph has three non-horizontal lines through the x-axis, which are important for the response and include D, E and F, respectively. On the interaction plot graphs, the colour and shape of the points differ between statistically significant and statistically insignificant effects. On this plot, the main effects for factors D and $\mathrm{E}$ are statistically significant at the 0.05 level.

Additive manufacturing is a new group of technologies that, although still evolving, are projected to exert a profound impact on manufacturing. They can give industry new design flexibility, and shorten time to market. All AM technologies involve several processes, but these processes are often similar. In 
general, AM technologies involve eight different stages, which include creating the CAD model, converting this design to the STL format, transferring this format to the AM machine, configuring the machine, building parts, removing the pieces produced in the machine, and, if necessary, post-processing and using applications for additional treatments, such as painting and priming (Kumbhar and Mulay, 2018; Wong and Hernandez, 2012).

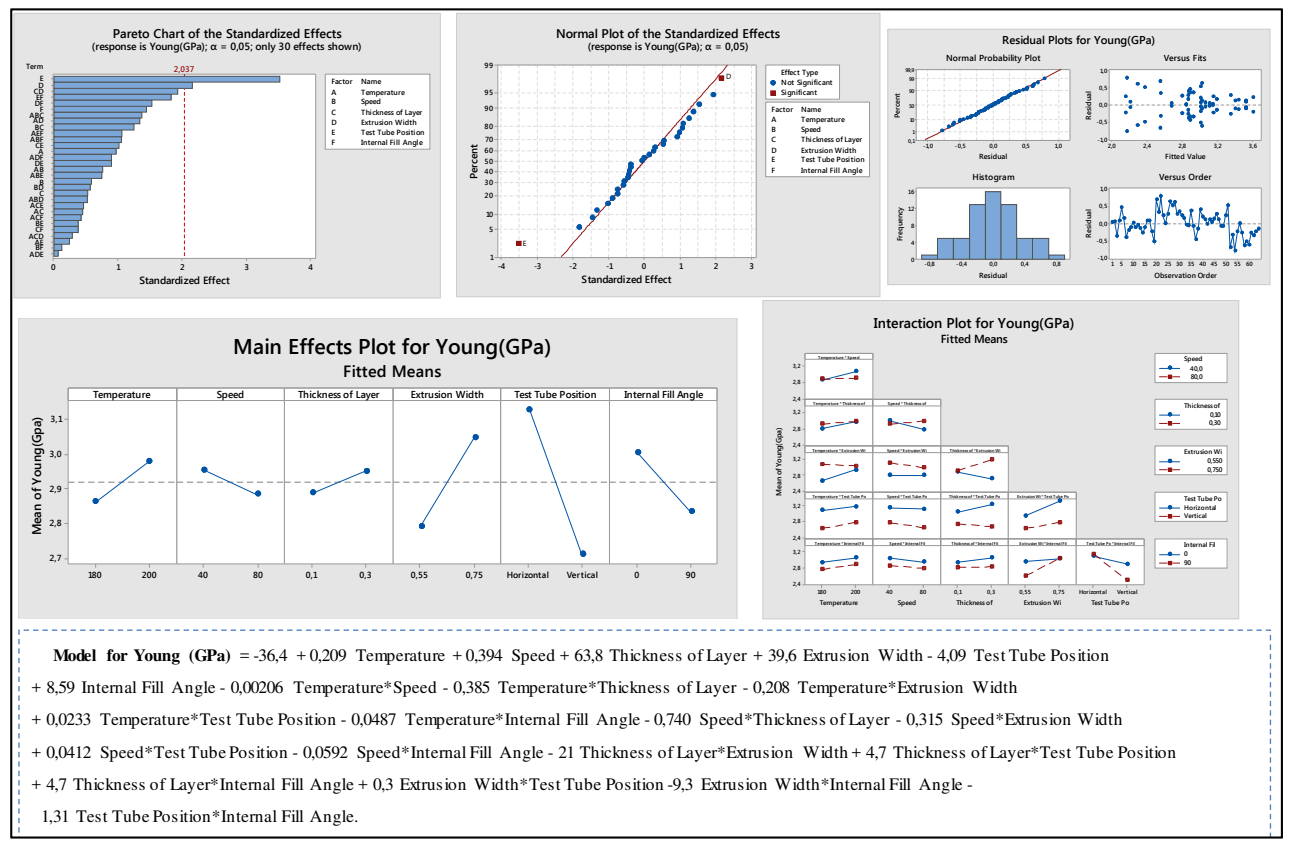

Figure 8 - Summary of Results for the First Response Young Modulus (GPa)

\section{Second answer: Break in tension $(\mathrm{MPa})$}

Figure 9 shows a summary of the results for the second answer: break in tension (MPa). A normal plot analysis indicates that D is located at the left side of the red line, which indicates that $\mathrm{D}$ has a positive effect. At the same time, DE has a negative impact on the response, referred to as a break in tension. The main effects graph shows that the lines are not parallel to the $\mathrm{x}$-axis for thickness of layer (C), extrusion width (D), or test tube position (E); however, clearly, the effects are more visible for extrusion width (D), which is a significant variable for that response. With the highest mean of break in tension, the level of extrusion width is the highest level of the variable at $0.75 \mathrm{~mm}$.

The variables of temperature, speed internal fill angle are in striking distance of the horizontal mean line in the mean effect graph. Therefore, interaction plot graphs are useful in determining which level they interact with. For temperature at the speed of $80 \mathrm{~mm} / \mathrm{sec}$, the interaction graph has the highest mean, so, the temperature is $200^{\circ} \mathrm{C}$. As mentioned, DE has at significant effect on the response break in tension. When the interaction graph is displayed according to understanding of the integrated effect while variable $\mathrm{E}$ is horizontal (symbolised 
by the blue line), variable $\mathrm{D}$ has the value $0.75 \mathrm{~mm}$, which is the highest level of extrusion width.

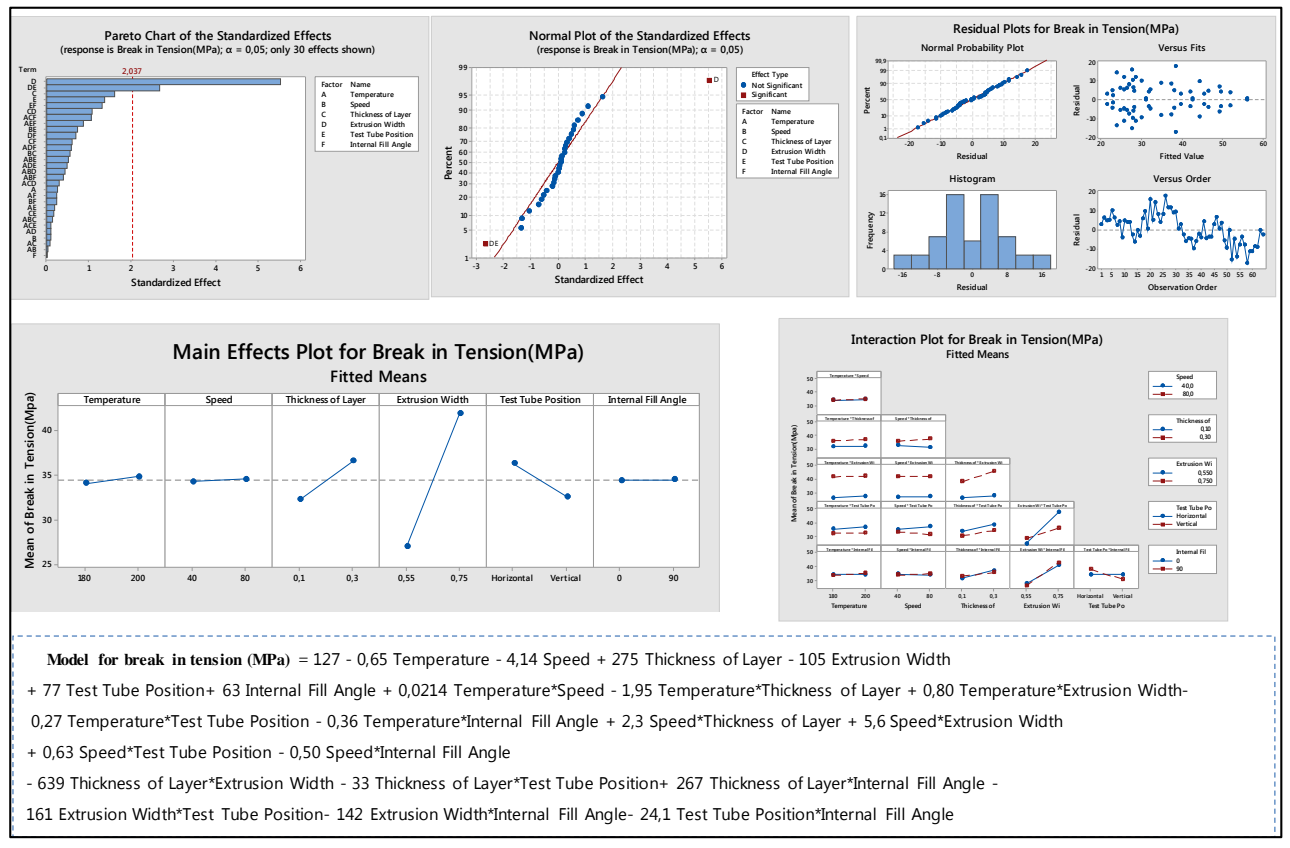

Figure 9 - Summary of Results for the Second Response Break in Tension (MPa)

\section{Third answer: Breakage deformation}

Figure 10 shows the summary of the results for the second and third answer: breakage deformation and break in tension (MPa). In the normal plot graph and Pareto chart, only extrusion width (D) has a significant effect on breakage deformation. Moreover, the main effect plot has an intense passing line, which belongs to the extrusion width. The line is not parallel to the $\mathrm{X}$ line. Process (D) has a positive standardised effect. When the process changes from a low level to a high level of the factor, the response increases. With the highest mean of breakage deformation, crucial variable $\mathrm{D}$ has a significant effect on response and must be $0.75 \mathrm{~mm}$, which is the highest level of that variable.

In this interaction plot, the lines are not parallel. This interaction effect indicates that the relationship between temperature and speed depends on the value of the temperature range. For example, if the speed (B) $40 \mathrm{~mm} / \mathrm{sec}$ is chosen, then temperature (A) $200^{\circ} \mathrm{C}$ is associated with the highest mean breakage deformation. In other respects, if the speed $80 \mathrm{~mm} / \mathrm{sec}$ is chosen, then the temperature $180^{\circ} \mathrm{C}$ is associated with the highest breakage deformation. 


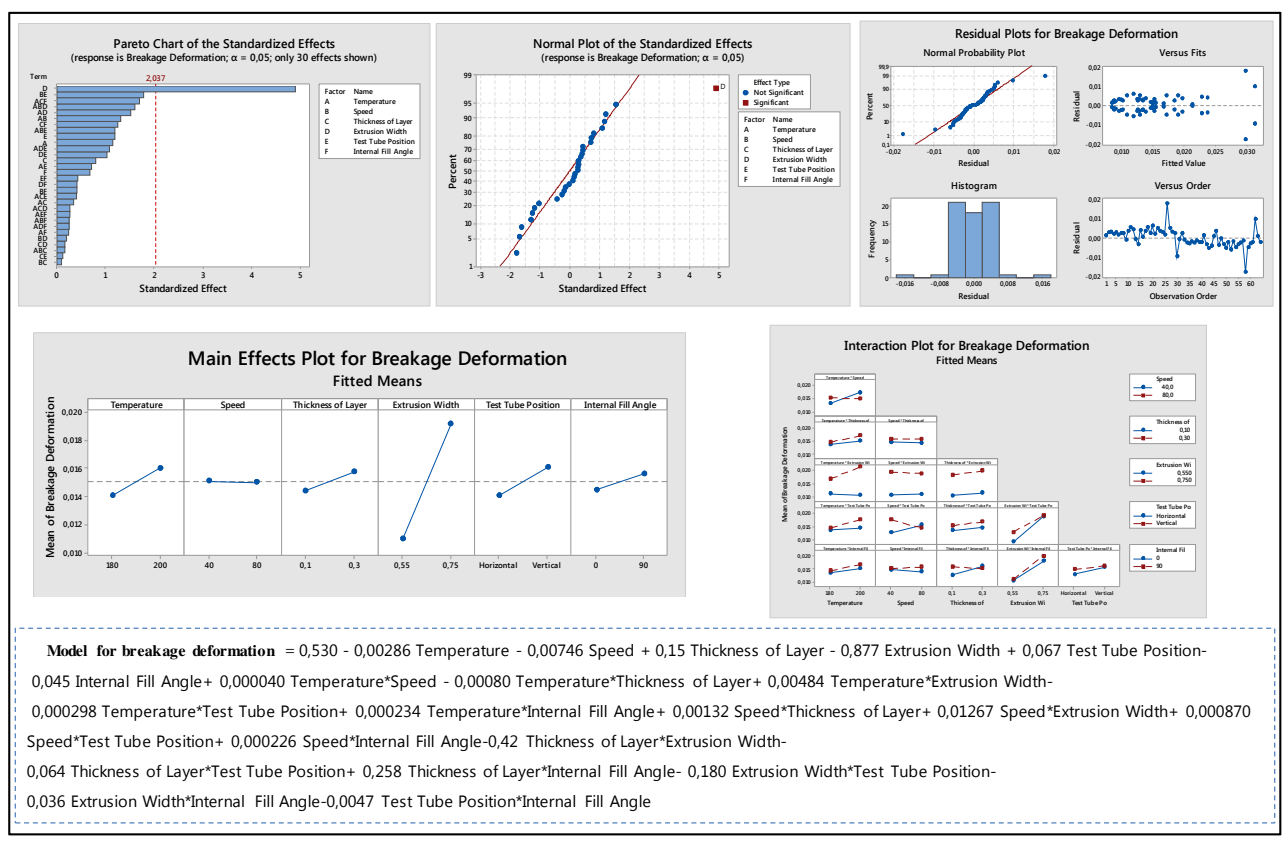

Figure 10 - Summary of Results for the Third Response Breakage Deformation

\section{Phase 6: Improvement via confirmation experiments of the case study}

The optimisation of the process response was carried out by pivoting the values of variable extrusion width (D) and test tube position (E) together as 'DE', which had a negative effect on the response. At the same time, D had an individual positive effect on the response. Thus, the variable level of $\mathrm{E}$, which was founded 'horizontal', can alter into the 'vertical' by minimising the negative effect of 'DE' on the response. Other variables were not as significant as D. Therefore, any type of change in these variables would not affect the response as expected.

The software Minitab 18 allowed us to define the optimal level of the variables, taking into account all the answers. Figure 11 shows the levels to be programmed for each of the variables to maximise the results of all the responses. The proposed levels for all the answers were temperature (A) $180^{\circ} \mathrm{C}$; speed (B) 40 ; thickness of layer (C) 0.3; extrusion width (D) 0.55; test tube position (E); and horizontal, internal fill angle (F) $0^{\circ}$. The expected results in these conditions for each response would be the following: breakage deformation 0.0022 , break tension 56.20, and Young modulus 4.2. 


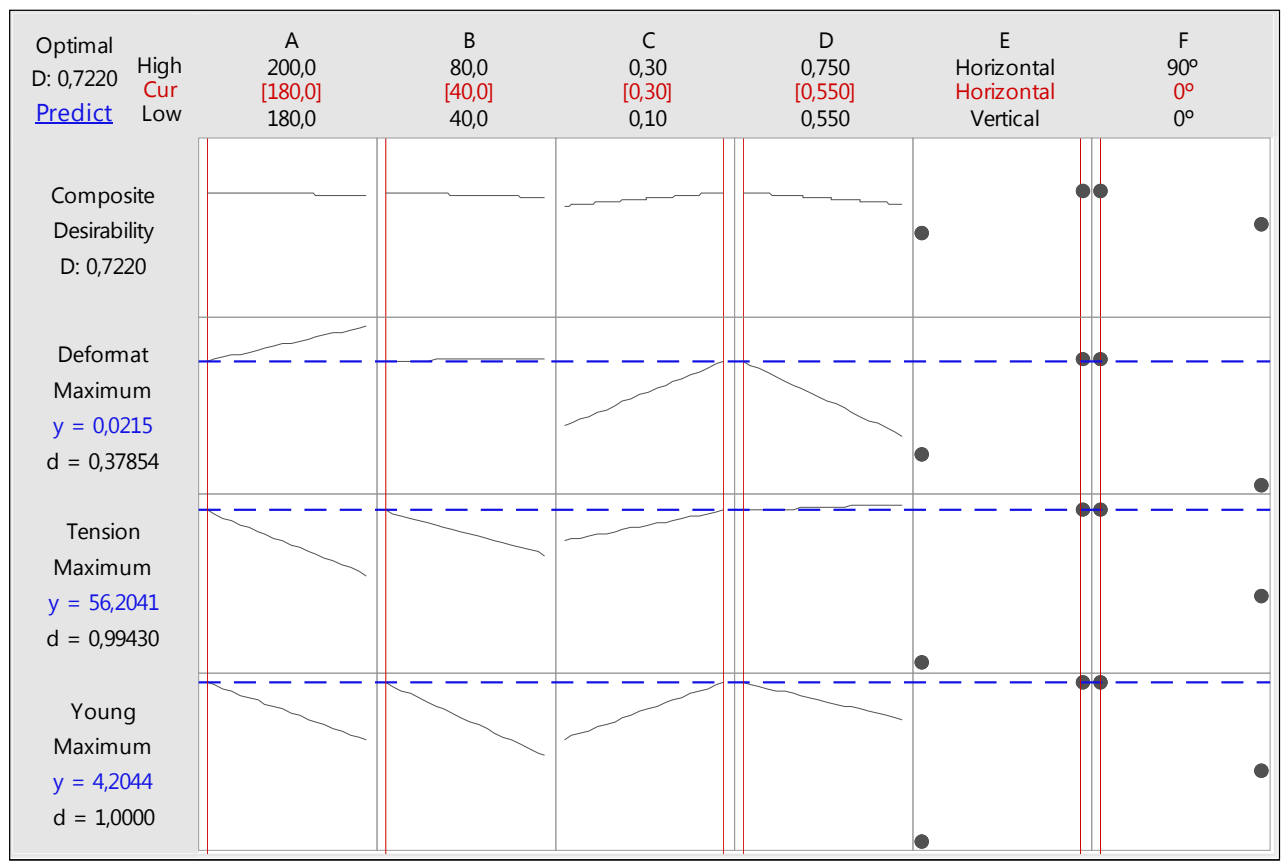

Figure 11 - Levels for Each of the Variable to Maximise All the Responses

(Minitab 18)

\section{Phases 7-8: Control and standardisation of the case study}

Once the significant factors that affect the process were defined, and the levels that improve the response were indicated, the process was standardised by establishing controls to maintain the factors at the appropriate levels. Subsequently, the results were contrasted in the application of two real cases.

To validate and standardised the parameters identified in the study, the results were contrasted by manufacturing two moulds: one to manufacture skateboards (Figure 12) and one for drone cases (Figure 13) with the vacuum-assisted infusion process. Through this application, the validity of the identified parameters was verified since the manufactured modes were manufactured at the specified speed and quality levels.

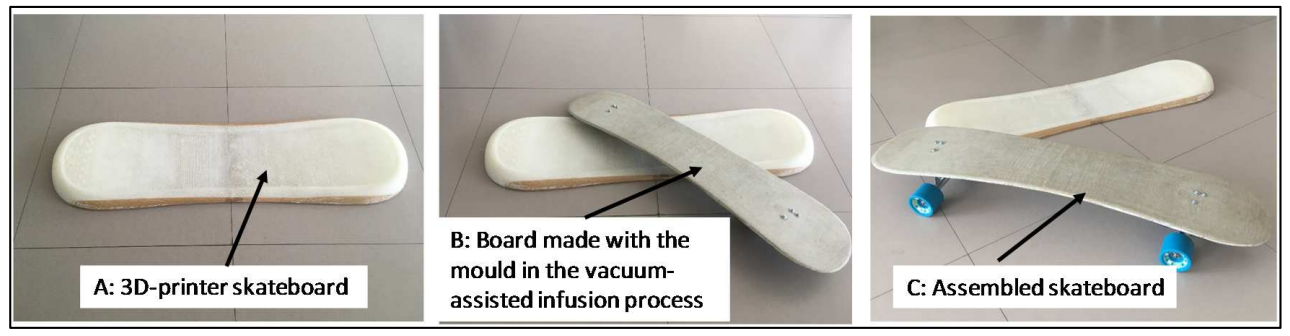

Figure 12 - Mould for a Skateboard 


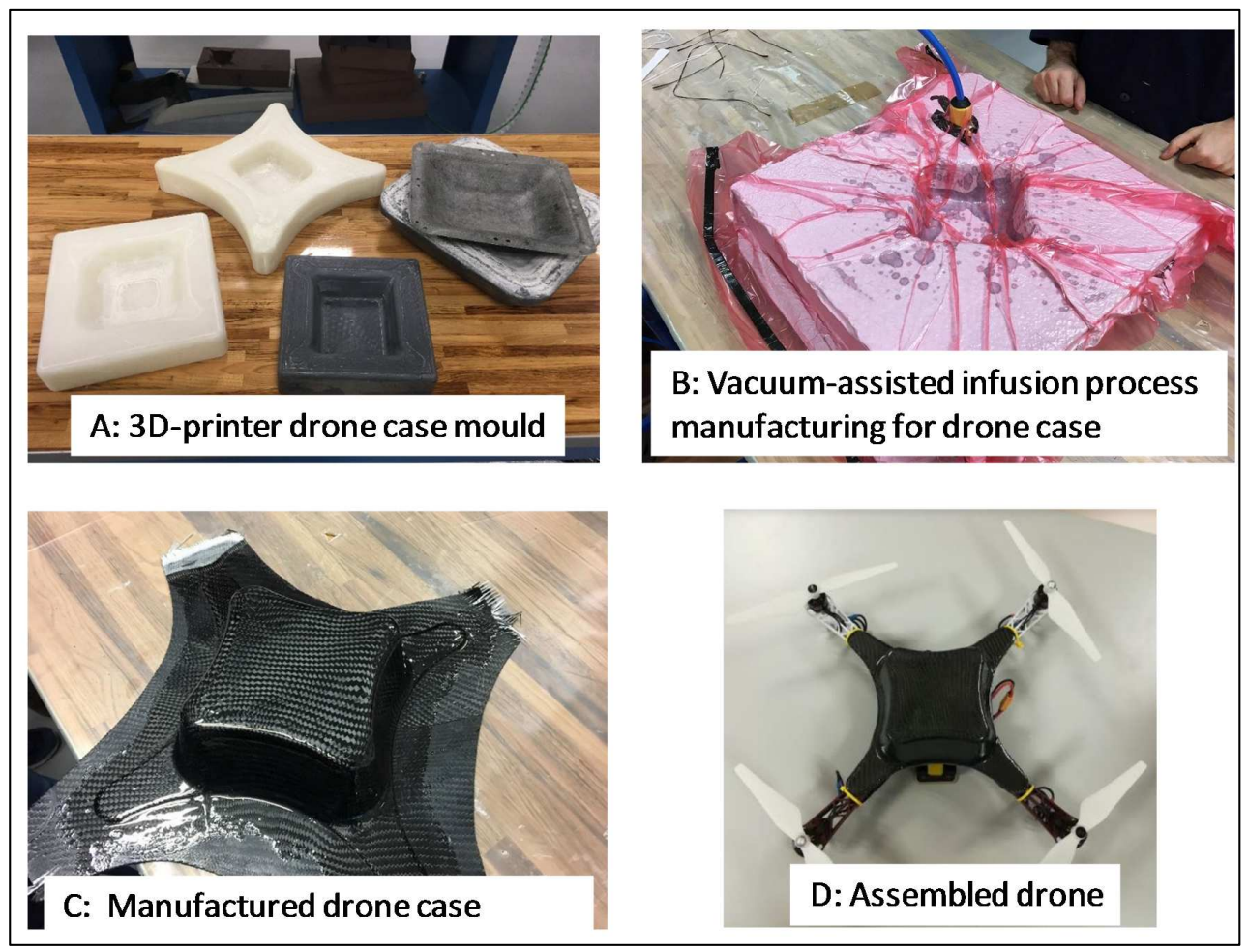

Figure 13 - Drone Case Mould

\section{CONCLUSIONS}

This article has demonstrated the importance of the use of experiment design methods to optimise methodologies through minimal experimental effort. It has also demonstrated the validity of the standard process followed by showing how to address the planned experimentation of any industrial process, enabling efficient use of the experimentation methods so that efforts to develop an understanding of the process are optimised. The applied methodology also allows for the development of the ability to deploy an appropriate experimental design to obtain maximum information with minimum experimental effort.

The best combination of levels for the three analysed outputs was identified, which was tested by manufacturing real products using the desired technical characteristics. The ideal combination is temperature (A) $180^{\circ} \mathrm{C}$; speed (B) 40; thickness of layer (C) 0.3; extrusion width (D) 0.55; test tube position (E); and horizontal, internal fill angle (F) $0^{\circ}$. The results have been confirmed by their application in the manufacturing of two moulds applied in a vacuum-assisted infusion process. An analysis was carried out with the Minitab 18 statistical software to determine how the data might be exploited.

The same experimental setup and analysis techniques can be readily applied to different 3D technologies, and the corresponding best setting of the various 
control parameters can be obtained. The results of the case study provide a stimulus for the wider application of experimental techniques in organisations, which can use the steps of the presented methodology. Future research might consider how to carry out designs based on the proposed methodology in an iterative way that guides the execution of the experimental process sequentially, gradually acquiring knowledge based on previous experimentation.

\section{REFERENCES}

Anitha, R., Arunachalam, S. and Radhakrishnan, P., 2001. Critical parameters influencing the quality of prototypes in fused deposition modelling. Journal of Materials Processing Technology, [e-journal] 118(1-3), pp.385-388. DOI: 10.1016/S0924-0136(01)00980-3.

Chepelev, L., Giannopoulos, A., Tang, A., Mitsouras, D. and Rybicki, F.J., 2017. Medical 3D printing: methods to standardize terminology and report trends. 3D Printing in Medicine, [online] Available at: <https://doi.org/10.1186/s41205-0170012-5> [Accessed 31 March 2020].

Cruz, F.A., Boudaoud, H., Muller, L. and Camargo, M., 2014. Towards a standard experimental protocol for open source additive manufacturing. Virtual and Physical Prototyping, [e-journal] 9(3), pp. 37-41. DOI: 10.1080/17452759.2014.919553.

Dwivedi, G., Srivastava, S. and Srivastava, R., 2015. Analysis of Barriers to Implement Additive Manufacturing Technology in the Indian Automotive Sector. International Journal of Physical Distribution \& Logistics Management Rajiv, 47(10). DOI: 10.1108/IJPDLM-07-2017-0222.

Gausemeier, J., Wall, M. and Peter, S., 2013. Thinking ahead the Future of Additive Manufacturing - Exploring the Research Landscape. [pdf] Paderborn: Heinz Nixdorf Institute. Available at: <https://dmrc.unipaderborn.de/fileadmin/dmrc/Download/data/DMRC_Studien/DMRC_Study_Pa rt_3.pdf > [Accessed 31 March 2020].

Gibson, I., Rosen, D. and Stucker, B., 2015. Additive Manufacturing Technologies: 3D Printing, Rapid Prototyping, and Direct Digital Manufacturing. Second Edition. New York, NY: Springer. DOI: 10.1007/978-14939-2113-3.

Guo, N. and Leu, M.C., 2013. Additive manufacturing: Technology, applications and research needs. Frontiers of Mechanical Engineering, 8(3), pp.215-243.

Harris, R., 2019. Additive manufacturing research group. Loughborough University. Available at: $<$ https://www.lboro.ac.uk/research/amrg/about/the 7categoriesofadditivemanufact uring/> [Accessed 29 May 2019]. 
ISO (International Organization for Standardization), 2012. ISO 527-2 Plastics - Determination of Tensile Properties - Part 2: Test Conditions for Moulding and Extrusion. Geneva: ISO.

Ituarte, I.F., Coatanea, E., Salmi, M., Tuomi, J. and Partanen, J., 2015. Additive Manufacturing in Production: A Study Case Applying Technical Requirements. Physics Procedia, 78, pp.357-366.

Khajavi, S.H., Partanen, J. and Holmström, J., 2014. Additive manufacturing in the spare parts supply chain. Computers in Industry, [e-journal] 65(1), pp.50-63. DOI: 10.1108/RPJ-03-2017-0052.

Kumbhar, N.N. and Mulay, A.V., 2018. Post Processing Methods used to Improve Surface Finish of Products which are Manufactured by Additive Manufacturing Technologies : A Review. Journal of The Institution of Engineers (India): Series C, 99(4), pp.481-487.

Li, Q., Kucukkoc, I. and Zhang, D.Z., 2017. Production planning in additive manufacturing and 3D printing. Computers and Operations Research, 83, pp.1339-1351.

Lipson, H., Lyons, B., Bengio, S., Ochsendorf, J., Pyke, C., Leuthardt, E.C., and Weiland, J.D., et al., 2012. Manufacturing in Aerospace: Examples and Research. Frontiers of Engineering, [online] Available at: $<$ https://www.nap.edu/catalog/13274/frontiers-of-engineering-reports-onleading-edge-engineering-from-the> [Accessed 31 March 2020].

Moreau, C., 2018. Annuaire Des Statistiques Des Hydrocarbures En Côte d'Ivoire. [pdf] Ministère Du Pétrole,De L'énergie Et Du Développementdes Énergies Renouvelables. Available at: $<$ http://dghstatistiques.ci/assets/documents/annuaire/Annuaire-DGH-2018v3.pdf $>$ [Accessed 31 March 2020].

Narang, R. and Chhabra, D., 2017. Analysis of Process Parameters of Fused Deposition Modeling (FDM) Technique. International Journal on Future Revolution in Computer Science \& Communication Engineering, 3(10), pp.4148.

Office of Technology Transition, 2019. Additive Manufacturing: Building the Future. Washington: Office of Technology Transition.

Prasad, M.M., Krishna, N.J. and Venkatasubbareddy, O.Y., 2014. Improving the Surface Roughness of FDM Parts By using Hybrid Methods. International Journal of Engineering Research \& Technology, 3(12), pp.650-654.

Rayegani, F. and Onwubolu, G.C., 2016. Fused deposition modelling (FDM) process parameter prediction and optimization using group method for data handling (GMDH) and differential evolution (DE). The International Journal of Advanced Manufacturing Technology, [e-journal] 73, pp.509-519. DOI: 10.1007/s00170-014-5835-2. 
Sood, A.K., Ohdar, R.K. and Mahapatra, S.S., 2010. Parametric appraisal of fused deposition modelling process using the grey Taguchi method. Journal of Engineering Manufacture, 24(1), pp.135-145.

Tofail, S.A.M., Koumoulos, E.P., Bandyopadhyay, A., Bose, S., O`Donoghue, L. and Charitidis, C., 2018. Additive manufacturing: scientific and technological challenges, market uptake and opportunities. Materials Today, 21(1), pp.22-37.

Unzueta, G., Orue, A., Esnaola, A. and Eguren, J.A., 2019. Metodología del diseño de experimentos. Estudio de caso, lanzador. Dyna, 94(1), pp.16-21.

Venkatasubbareddy, O.Y., Siddikali, P. and Saleem, S.M., 2016. Improving the Dimensional Accuracy And Surface Roughness of Fdm Parts Using Optimization Techniques. IOSR Journal of Mechanical and Civil Engineering, 16(053), pp.1822.

Wiemer, H., Schwarzenberger, M., Dietz, G., Juhrisch, M. and Ihlenfeldt, S., 2017. A Holistic and DoE-based Approach to Developing and Putting into Operation Complex Manufacturing Process Chains of Composite Components. Procedia CIRP, 66, pp.147-152.

Wong, K.V. and Hernandez, A., 2012. A Review of Additive Manufacturing. International Scholarly Research Notices, [e-journal] 2012, 10p. DOI: $10.5402 / 2012 / 208760$.

\section{ABOUT AUTHORS}

José Alberto Eguren - (J.A.E.) Mondragon University, Spain, Mechanical and Industrial Production department, e-mail: jaeguren@mondragon.edu, Author's ORCID: 0000-0002-4127-8776.

Aritz Esnaola - (A.E.) Mondragon University, Spain, Mechanical and Industrial Production department, e-mail: aesnaola@dumondragon.edu, Author's ORCID: 0000-0003-0955-7545.

Gorka Unzueta - (G.U.) Mondragon University, Spain, Mechanical and Industrial Production department, e-mail: gunzueta@mondragon.edu, Author's ORCID: 0000-0002-6889-3293.

\section{AUTHOR CONTRIBUTIONS}

All authors contributed equally to this article. J.A.E., A.E and G.U. conceptualization, resources, validation, writing review and editing. 


\section{CONFLICTS OF INTEREST}

The authors declare no conflict of interest. The funders had no role in the design of the study; in the collection, analyses, or interpretation of data; in the writing of the manuscript, or in the decision to publish the results.

(C) 2020 by the authors. Submitted for possible open access publication under the terms and conditions of the Creative Commons Attribution (CC-BY) license (http://creativecommons.org/licenses/by/4.0/). 